\title{
A Model For The Regulation Of Technology Innovation
}

\author{
Vaughn Alliton, (E-mail: Valliton@pace.edu), Pace University
}

\section{INTRODUCTION}

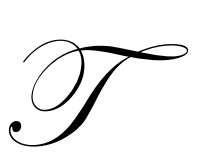

echnology has had an impact on society for centuries. Martin Luther wouldn't have stated the Protestant Religion without the help of Gutenberg's Printing Technology.(Spar, 2001) In the last few centuries the affect that technology has had on business and commerce has been increasing and at a more rapid pace, just within the communications area, the pace from Telegraph, to Telephone, to Radio, to Television, to the Internet, ad now Wireless. We are now to a point that the economy is driven, to a great extent, by the technology that underlies it, and the changes to that technology drives more and more of the economic growth. It is, therefore, important to understand not only how technology affects the economy but also how to improve the technology innovation process so that the continued growth of the economy isn't stagnated but encouraged to grow at its fastest reasonable pace. This paper lays out, first, ways in which the economy is and has been affected by technology, second, how technology evolves and is incorporated into businesses and the larger economy, and third, a model for government involvement in this innovation cycle, in hopes that the cycle can run its most efficient and effective course.

\section{TECHNOLOGY AND THE ECONOMY}

Technology has changed the face of human civilization for centuries. People found ways to use machines and tools to assist them with their work, harking back to the invention of the stone wheel and discovery of rubber and all of its uses. Not only has technology been around and been important to everyone's lives and societies' productivity, but it has also been the source of concern and speculation for Economic Theorists for some time. Karl Marx dreamed of a society that would see individuals working with tools and machinery to help them produce much more than they needed to survive, so that they could have time to create and provide for everyone else, even those who lagged behind in their productive processes. Joseph Schumpeter was an economist that took technology even further: He felt that technology had a great impact on the economy and the process of capitalism. Technology has been a driving force behind change(Spar, 2001), and that change has rewritten the basis of the economy and economic thought repetitively, and it is time to update the economic theories again.

\section{Creative Destruction}

Joseph Schumpeter also wrote about the basis of technology was that technology constantly replaced itself; through a process he called Creative Destruction.(Schumpeter, 1942) He was an early Theorist that identified that one of the tenets of Technology is that new technologies have a tendency to totally replace the existing technology.(Sengupta, 2001) This replacement has an economic impact especially to those businesses dependent on the older technology. A contemporary example of how a new technology can replace an existing technology is RFID and the Bar Code. The existing Bar Code technology has been in use for decades; it was a significant improvement for retail sales when it was introduced. It allowed sales to be made with fewer human errors and also increased the speed of purchase for customers. The Bar Code technology continues to evolve, with cheaper hardware for bar code reading. Meanwhile, the US is updating its system by adding more digits which allows for information to be associated with each bar code. (Saccomano, 2003) Radio Frequency Identification technology (RFID) was developed recently; it is expected that as the technology matures and is used by more manufacturers and retailers, it will replace the printed Bar Code.

RFID is built from a new method to transmit information, and it allows for considerable more information to be associated with each product. RFID is based on an extremely low energy radio transmitter, about the size of a 
grain of sand, to be integrated into the items that are sold. This transmitter not only reduces the need for a physical scan of the product at a checkout counter, it actually transmits the product's information. Thus, the product can't be hidden by the individual who has the item. This not only makes the purchase process more efficient; it reduces shoplifting and theft. RFID lets consumers collect all of their purchases and place them directly in their bags or walk straight out of the store without stopping to have each item registered. Consumers just pay the amount necessary for the purchases at a kiosk or teller.(Retail Merchandiser2003).

It is fairly straightforward to understand how this new technology, once the mass production and cost issues are settled by producers, would easily supplant the printed Bar Code. RFID has Wal-Mart, the world's largest retailer, driving it. Wal-Mart wants its top 100 suppliers to deploy RFID by January 2005. Though not a likely scenario in that timeframe, it will happen soon.(Wailgum, 2004) This is the process of creative destruction. Once the RFID is in place and used in mass, the Bar Code will become totally obsolete. The affect on the economy is yet to be fully understood, although those businesses that are dependent on Bar Code technology will have to adjust or may lose most of their market.

Creative Destruction is an interesting phenomenon that affects technology and technology innovation, but with the growing affect that technology has on commerce and the economy it is expected to be the topic of more discussion. As more and more of the products and services that make up the US economy become automated and dependent on technology and technology innovation for growth and advancement, the fact of creative destruction will have a greater impact on the economy. This is not necessarily bad, as any change is not necessarily bad, but it does bring new challenges to society and the economy to adjust to these changes.

\section{Productivity and Innovation}

Technology innovation not only provides greater functionality and faster throughput for processes, it is important to the economy and society because of its effect on Productivity. The application of technology to manufacturing and corporate activities increases the productivity of workers. It allows companies to create more output with the same or fewer employees. This saves companies money and reduces operating costs. This also allows a society to utilize human resources more efficiently. It would be rational then to assume that firms would utilize all existing technologies as well as new ones as soon as they become available. Organizations would implement all new technology if it were free and had little or no risk to implement, but since it isn't it requires investment. More than hardware, the training of workers and the strategic execution on the process to integrate the new technology into the current activities require significant investment. A decision that every firm has to make: at what point is it worth investing in the new technology that is going to render the one in use obsolete? This is no easy decision as there is tremendous risk and the possibility of tremendous reward, for users and manufacturers of technology.

There have been a number of developments in the area of innovation and technology acquisition, but some recent work shows that the level of competition in an industry has a significant impact on firms' willingness to jump into new technologies. A two-year study performed by McKinsey Global Institute found that firms which compete in the most competitive industries gain the most productivity from technology innovation.(Farrell, 2003) The study found that although the six most competitive industries in the US made up only $32 \%$ of the nation's GDP in the 1990 's, they accounted for $76 \%$ of the productivity gains. This reinforces the concept that companies will implement and invest in technology innovations and invest in new technology if they are forced to, in this case by competition within their industry. Presumably, they will also invest when they feel that the risk reward tradeoff is more favorable as well.

\section{TECHNOLOGY ERAS}

Schumpeter's Creative Destruction needs a model for how organizations can evolve and adapt through these destructive cycles. Philip Anderson and Michael Tushman (Anderson \& Tushman, 1991) developed one using the concept of Technology Eras. Their model, influenced by Richard Foster's S-curves, divides the evolution of technology into Eras. They felt that their model was necessary to help organizations understand the ebb and flow of technology as new innovations supplant existing platforms and technologies. 
The Technology Eras starts each cycle with the introduction of a new technology to the economy. Referred to as a "Technological Discontinuity," it is a complete separation from the existing technology. From this Technological Discontinuity arises an Era of Substitution. During this Era of Substitution innovators begin to apply the new technology with multiple designs for how to utilize the new technology. As users start to adopt the different applications of the new technology, the industry initiates an Era of Design Competition, each innovator competing for the most popular design. As the new technology gains market acceptance, one Dominant Design surfaces. Once the Dominant Design is obvious, competing designs are abandoned as technology manufacturers and users embrace the Dominant Design. The final phase of the cycle is an Era of Incremental Change. It is in this final Era of the cycle for the new technology where firms add complementary technologies to the Dominant Design and begin to make incremental improvements on it. This final Era continues until yet another novel technology is invented or discovered totally replace the technology of the current cycle and, thus, initiating a new cycle of its own.

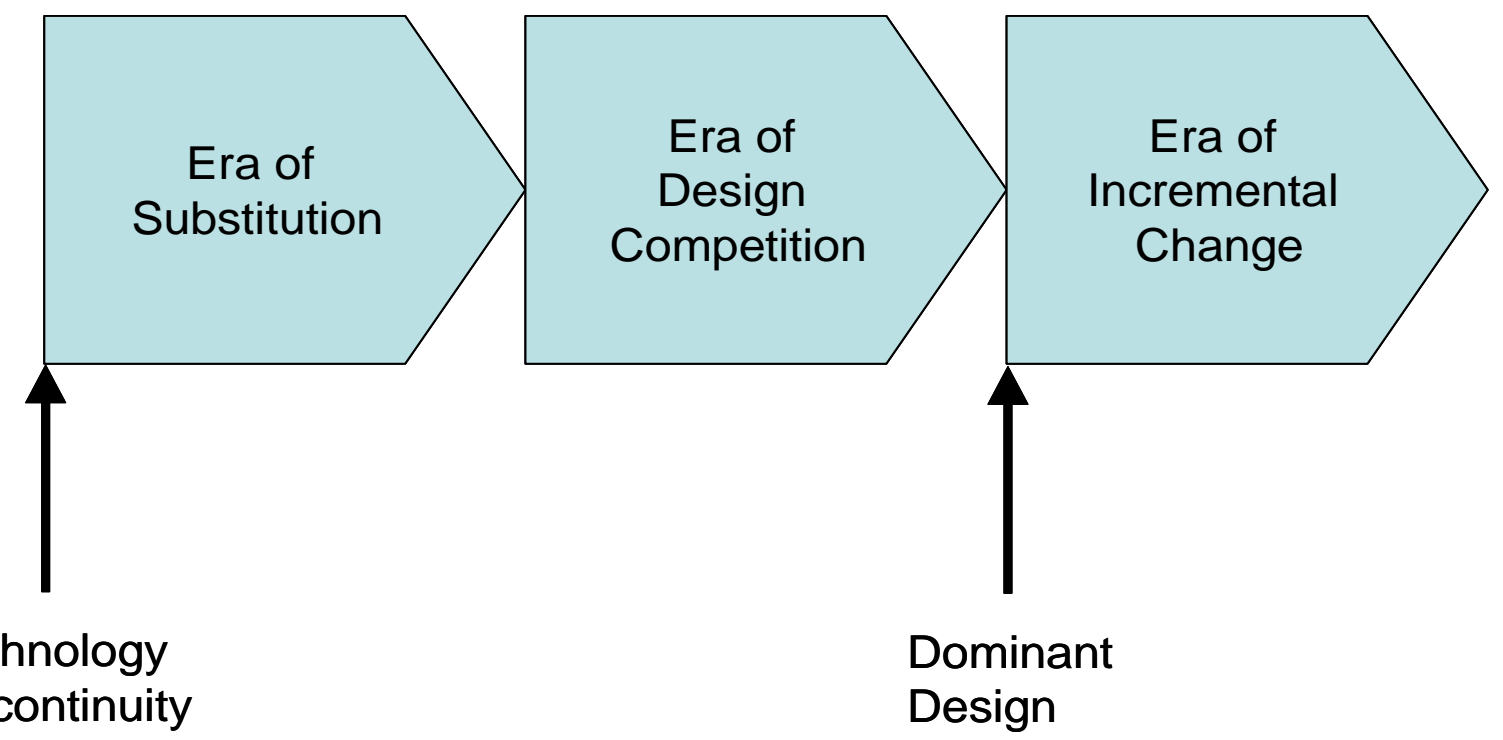

Figure 1(Anderson et al., 1991)

\section{Innovation Challenges}

During the Era of Substitution, firms that are entrenched in the existing technology's Dominant Design will fight against the newcomer. They have considerable investments in the existing technology and would prefer to continue to improve on it rather than to experience the Schumpeterian Creative Destruction. Stuart Hart and Mark Milstein looked at this from an industry perspective and found the same inter-firm tension, which they discussed in terms of Continuous Improvement vs. Creative Destruction. (Hart \& Milstein, 1999) As many of the researchers and economists have voiced since Schumpeter's original idea, there are considerable profits at stake for the old as there is potential for the new. But there is also the chance that firms overly reliant on the old technology will no longer be able to compete.(Kassicieh \& Walsh, 2004) Therefore, there are often strong challenges to the new technology from the major "players" involved in the old technology to just use incremental advances on the old technology rather than risk moving to a brand new technology. Although the old technology improvements occasionally hold off the innovation, they ultimately end up getting replaced. 


\section{ECONOMY}

Technology has always had an impact on the economy; that didn't start in the 1990's with the introduction of the PC to white collar workers. Technology has not only been used by workers and society heavily throughout the past few centuries, it has also often defined and driven the direction of society; for example the introduction of the printing press and direct access to information rather than being controlled by the Catholic Church.(Spar, 2001) Society has been given new opportunities and seen cultural revolutions offered by the availability of new technology. People have also been freed by technology. Technology has improved the quality of life and has introduced completely new sets of challenges for people and governments. New technologies have opened profit opportunities and the government has had to changed the rules of commerce in order to maintain balance and control which has shifted significantly due to new technologies.(Spar, 2001) Although productivity has been a driving force behind the need for new technology, innovation has taken place in many areas. There is a sound truth in the common phrase, "Necessity is the Mother of invention." Here are just a few important examples of how technology has affected and changed society and commerce in the past few centuries.

\section{9th Century}

Although the 19th Century is not normally associated with times of significant technology utilization; technological advances had significant impacts on business, society and the economy. More complex machinery was introduced, changing what workers did and how much work they could complete in a day. Transportation changes, driven by new technologies, changed the distribution of society and the distribution processes of agricultural products. The addition of machinery to activities in the 19th Century had a significant impact on the quality of life of society as a whole. Although from an individual level the addition of technology might not seem to be an improvement, as a whole society enjoyed the surpluses produced by the addition of technology and the changes in the physical requirements of work. Machines took on more of the dangerous and physically strenuous activities---although this did not insulate $19^{\text {th }}$ Century workers from danger in the work place--- it did improve the lives of many.

\section{Agricultural evolution}

The 19th Century was mainly a period where work was focused on agriculture. The addition of technology not only altered the work processes, but also increased the number of people that could be fed and clothed off the same of land utilizing less labor, e.g. the Cotton Gin. This change allowed people to focus on other activities and processes beyond those necessary just to survive. As with all Creative Destruction, once the technology is introduced to the process, there is no turning back to the old methods. Once workers found ways to be more productive and to produce more with the same amount of time and effort, they wouldn't be willing to return to a more manual, less productive method without the technology.

\section{0th Century}

The $20^{\text {th }}$ Century is mostly characterized by manufacturing. The addition of machinery and technology to the process of making goods transformed the economy, in a relatively short period of time, from being agriculture-based to manufacturing-based. It also changed the demographics of populations, bringing many more people to the cities to work in factories from the rural agricultural areas. This is not to say that technology and innovation did not have an effect on agriculture. For example, the US produced more than enough food to feed the country as the percentage of people involved in farming dropped to a very low percentage of the population, and this was based on drastic improvements in farming machinery, e.g. the Combine, The Mechanized Planter, etc.

Technology and technology innovation not only changed the products and processes that were common in the $19^{\text {th }}$ Century, it changed the entire society. Business and society's focus on manufacturing as the productive work method for most workers not only changed the productive capacity for the society, but changed the way people work together, and related to ownership. People went from fairly isolated agricultural work where they owned or controlled the land, to organized group labor where they received a wage for their activities and were directed by the owners of the means of production. Workers needed different skills and more education to prepare them for their new roles. 
They also needed to be better prepared to work with more and complex machinery which would do more of the work, and free workers up to organize and drive the work, rather than to perform do the manual task.

\section{Manufacturing revolutions}

Manufacturing changed not only the staples of goods, such as iron ore production and the creation of new building materials, but also in the productivity of workers, such that more and more products per worker could be produced and the balance of workers could start to shift from manufacturing to services, by the end of the $20^{\text {th }}$ Century.

The focus on manufacturing also drove technology changes. Factory owners wanted to produce more without driving up costs, and they found that the application of technology could accomplish that. They also found that they needed more research and ways to develop products around new capabilities. The $19^{\text {th }}$ Century focused on doing more with what existed, but the $20^{\text {th }}$ Century ushered in the concept of researching new methods, materials and product development to find more uses for what could be made. Workers fulfilling R\&D roles and very specialized and highly trained roles evolved to become more common. Work became even less manual and more skilled. The evolution of technology innovation not only affected commerce it also affected the basis of society; education, skillsets, and diversity all changed as the technology innovations allowed for and pushed more change.

\section{1st Century}

Although the $21^{\text {st }}$ Century is just getting started, it is obvious that industries and the economy that will define the century are very different from the past. It could be argued that from the perspective of the model for work and the economy, this century actually began in the latter half of the 1990's, much the same as from this model's perspective the $20^{\text {th }}$ Century actually started in the late 1800 's. This is giving the century a perspective around how the economy works and the driving forces that move it, rather than just a calendar. The defining paradigm of the $21^{\text {st }}$ Century will undoubtedly be the integration of networked computing, miniaturization, and Knowledge Workers. These items will be embedded in more and more aspects of the economy and every product and service that comprise commerce. The integration of Information Technology and the further automation of every aspect of life are rapidly changing every commercial activity involving firms. It creates markets for technologies yet to be invented and will wipe out many industries as they currently exist; more Creative Destruction.

A further defining aspect of the $21^{\text {st }}$ Century is speed. In the $21^{\text {st }}$ Century everything will go faster and need to run faster than ever before. Products and services will be rated based on not only their speed of execution, but the speed of innovation and a rapidly shrinking product life cycle. The Japanese market will be a good proving ground, as it is already used to rapidly changing and evolving products. This will rapidly spread to every corner of the globe as technology hardware and software are integrated into every part of people's lives.

\section{Knowledge Workers}

Another big difference from the previous century will be the type of work that it performed in the economy. The economy will be driven by knowledge workers and knowledge work. Knowledge workers are those individuals whose job is based on the application of a broad set of in-depth knowledge that is applied to problems and challenges as they occur. Some examples of these workers are software development engineers, hardware engineers, research scientists, lawyers, and doctors. Although these jobs are not new, they are increasingly becoming that basis of much of the economy and are the areas of job growth and economic expansion in the future.

Knowledge Management, believed to be first documented as a concept by Peter Drucker in 1959, was originally Dr. Drucker's term to describe what was later named Information Technology Management. (Professor Thomas Haigh, University of Pennsylvania, 2001) A more contemporary definition for Knowledge Management is the practice of transforming the intellectual assets of an organization into business value.(Agresti, 2000) This is a very broad definition and shows that the use of knowledge management has focused on a more specific area of the implementation of technology. It is focused on the use and reuse of knowledge held within an organization for 
productive activities. It is still very dependent on technology, but is a much more focused application. From Knowledge Management, we can derive a role of knowledge worker as someone who contributes to an organization through what one knows about a specialized body of knowledge and their ability to apply that knowledge to many different situations and activities, rather than through manual labor.(Noe, 2005) These knowledge workers and knowledge work are becoming an increasingly important part of business in the United States, especially as the economy becomes more services-based and less dependent on manufacturing.

\section{Technology-Driven Productivity}

The importance of technology and technology innovation to the economy was further linked by the Chairman of US Federal Reserve, Alan Greenspan. He has made this link a number of times, specifically in his discussions of the rapid growth of productivity in the accelerated economy of the late 1990's. (Dreazen, 2000; Greenspan, 1998) Alan Greenspan has used the application of technology to the workplace in a very similar form as that of the McKinsey Study (Farrell, 2003), to show that the economy is being driven by a rapid increase in productivity that are directly linked to the application of technology to business processes and actions.

The application of technology in the workplace, more specifically in knowledge workers, is the new driving force behind the economy. The broad base of manufacturing is now a shrinking portion of the US economy; it is no longer the dominant portion of US GDP. Loss of manufacturing jobs has ever decreasing effects on the US economy, but the application of technology to the service sectors and other areas, such as pharmaceuticals, are become the powerhouses of the economy. The government will take more notice of technology, as they have been, as it becomes the dominant force in the economy. The government has always been involved with the regulation of commerce and by its involvement technology,(Spar, 2001) but now that technology is becoming a driving force in and of itself, the government needs to change its perspective. The government has to take a proactive role in technology innovation, or it will not be able to moderate and focus the economy as it has in the past.

\section{GOVERNMENT}

Although many economists and most business leaders are very wary of any government involvement in economic activities, there most certainly is a need for government involvement, and it has always been there to some extent. The government needs to ensure that the market doesn't take control of society and that the citizens don't become objects that are a part of the profits of corporations, but rather that corporations serve the needs of society such that productivity can continue to increase and all of society can share the rewards of productivity growth not just the owners of corporations.

There are ways that the government can positively affect the technology innovation cycle, just the same as the US Federal Reserve has a role in monitoring and influencing the economy through the business cycles and investment through interest rates. Historically the US and state government involvement has been mainly via regulation and legislation, but also to some extent through funding. This involvement will be different in the $21^{\text {st }}$ Century; just like the involvement with the $20^{\text {th }}$ Century Manufacturing economy was different from that which was effective for the $19^{\text {th }}$ Century Agricultural economy. As the basis of the economy changes, so does the basis for government involvement. The hope is that the basis for government involvement can occur in a more planned and proactive manner, rather than the reactive manner that characterized the transition from the agricultural to manufacturing economies.

It is important to note that the government is not only an enforcer of rules and regulations on an economy, but is also part of and effected by that economy. It is also take a role as one of its drivers. As with the change from protecting commodities markets in the $19^{\text {th }}$ Century to the investment in military development and manufacturing in the $20^{\text {th }}$ Century, the government is affected by the drivers of the economy insofar as it effect those drivers. Recently, during the 2004 US Presidential Primaries and the General Election, the government selection process has itself moved some technology forward and instituted some very innovative uses of the new economy's technology; e.g. Weblogs, Internet payments, etc. 
The use of the Internet as a communication tool and a method to collect campaign contributions have significantly changed the dynamics of politics.(Baker, Green, \& Hof, 2004) Although the 2004 election cycle was the first foray into web-based communications directly to voters, electronic communications were first used in 1992 via email, though it didn't have a significant impact until 2004.(Conhaim, 2004) The Internet allows for greater communication from voters, unlike the model in the past which mainly focused on communication to voters, this twoway communication allows for very rapid changes in the popularity of candidates and the definition of a candidate's platform. The election process not only introduced new technology to a larger portion of society, it drove the acceptance of that technology, and the technology was improved from the experience with it. Politicians such as Arnold Schwartzenegger and Howard Dean used the technology to create a new communication model and also developed new technologies to improve the communications models capabilities. (Conhaim, 2004) This shows that the technology that is driving the economy is also influencing the government that is called upon to regulate it.

It is vastly important that the role of regulation of the new economy be positive in its involvement with the technology innovation cycle, such that it doesn't harm the development of the technology which it tries to nurture. There could be issues, because just as those companies that have a vested interest in a current technology platform, those politicians that don't understand the new technology will work against its adoption. Even if the government approaches the responsibility of technology innovation regulation with a desire for a positive outcome, there are significant examples of good intentions resulting in bad execution.

\section{Historic Involvement}

The US government is very involved with business and the economy through regulations and its regulators like the FDC, FAA, and FCC and numerous state-level commissions and regulators, The government also encourage domestic industries through protective tariffs as well as import limitations and requirements; it interrupts companies and their actions when the companies harm consumers or their industry, usually through court actions or state Attorneys General. The government also limits mergers and acquisitions when the actions are seen as anticompetitive; alternatively, it breaks up companies when they became destructive monopolies.

The government's involvement with technology has been as profound as its involvement in all other sectors of industry and the economy. This involvement has been through legislation and regulations, and to some extent via investment in research and development. It has worked well historically, but is becoming anachronistic as the speed of technology evolution increases: the reactionary aspect of legislation starts to cause more harm than good.

\section{Telecommunications Act of 1996}

The Telecommunications Act of 1996 (Telecomm Act), comparatively a short piece of legislation, had a very broad body of commerce and regulatory law put in place.(Aufderheide, 1999) It was a very aggressive stance attempting to bring the laws and regulations of commerce which directly relates to the transmission of content and communication, into a single body of legislation, similar to the 1934 Act. The Telecom Act attempted to bring together decades of legislation as disparate as the Cable Act and the AT\&T Consent Decree, as well as to encourage competition while controlling some portions of commerce, mainly those related to decency. The decency provisions were fairly quickly overturned, not for technology reasons but rather because of the difficulty in writing legislation around a concept which can actually be flexible in the minds of many people.

The basic challenge was a desire to allow the past 60+ years of legislation and regulations to be reorganized for all participants in the communications by technology industry. The general hope was that in bringing everything together, there could be a greater focus on competition and healthy growth for the all of the industries involved in communications and broadcasting. This is the objective but the problem with this legislation was that it tried to do too much and to write regulations for technology that was still evolving. Where it tried to take in to consideration all of the technology changes that had occurred, those technologies continued to change. The result was legislation that was supposed to help technology advance and commercial uses of that technology to compete more effectively actually ended up becoming obstacles to the objectives. 


\section{Recent Challenges - VOIP}

In 2004, eight short years after the writing of the Telecom Act, the entire communications technology environment has changed.(Quinton, 2004) Wireless telephony is slowly replacing much of the old copper wired system: as of $2003,23 \%$ of all voice traffic was transmitted wirelessly. When the Telecom Act was written, broadband communication was totally unexpected, as the Internet wasn't even a potential market or technology. The potential of the Internet was barely scratched when the Act was passed. Broadband, which developed out of the popularity of the Internet and IP communications opportunities, grew to $22 \%$ of households in 2003 and is expected to hit at least $27 \%$ in 2004 . Wireless telephony and broadband have changed many of the assumptions of technologybased communications, and there are many other: digital/interactive cable, IP telephony, and GPS. These technologies are based on totally different paradigms than existed in the world of the early 1990's. In writing legislation, not only is it totally unrealistic to be able to take into consideration the impact of technology that hasn't been invented yet, it is also too politically risky to gamble with chance when a destructive technology may be developed that could change the entire landscape.

\section{Digital Millennium Copyright Act}

The Digital Millennium Copyright Act (DMCA) followed the Telecom Act of 1996 in 1998. Although the focus and intent of the legislation was different than the Telecom Act, it still had overlaps with that legislation, and a number of government agencies and corporate lobbyists tried to have many of the DMCA provisions included in the Telecom Act. The DMCA covered four main areas: implementation of the World Intellectual Property Organization treaties; added liability limits for ISPs for online copyright infringement; provided exemption from copyright limitation for copies of software for maintenance and backup purposes; and gave exemptions for short-term recordings from copyright infringement under certain conditions.(The Computer Lawyer,1998; Elkin-Koren, 2000)

Although on the surface it would seem that, similar to the Telecom Act, the DMCA was intended to assist with the advancement of new technology and to increase competition and commerce; it was actually an example of the legislative process gone very wrong. The legislation was overly influenced by an older technology: the artistic recording distribution industry, in an attempt to kill off any creative destruction that new digital technology would have on their monopoly for artistic and creative works distribution. As technology advancements led to the destruction of many of the old retail and distribution models, the music and film distributors were concerned with maintaining their monopoly, and thus used the legislature to change the regulations that cover their analog technology and the copyright laws to ensure that no new technology could threaten their business model and profits. This is the opposite intent of the creative destruction cycle presented in the previous section that justified the need for the Telecomm Act of 1996.

This should serve as a strong warning that the firms that control the current technology will use any influence and opportunity that they can find to ensure that they get to keep their control and possible monopoly. The government needs to carefully guard against becoming the tool to stop innovation and new technologies.

\section{Education Challenge - TEACH}

There are other examples where Congress has realized that the legislation it passed was no longer appropriate for the current economic, technical or business environment, and have enacted new legislation to cancel or amend the previous legislation. The TEACH legislation is a great example where new legislation altered existing legislation, and an example where the Congress reacted extremely quickly. TEACH allows educators to broadcast digitally recorded material and alter it, which had been a direct violation of the DMCA.(Russell, 2003) The Congress quickly realized that its solution to the rapidly changing technology was the wrong solution and it was actually hurting education, where a greater sense of responsibility was realized. The change was obvious almost immediately, which is not normally the case, but makes for a much stronger example of government involvement in technology and its uses within the economy. 
The government is able to focus and direct the application and direction of new technology. Although it may not always contribute the most productive involvement, there is a precedent for the government's involvement. Having the government make a positive contribution to Dominant Design process would be very advantageous for society and the growth of the economy. The issue is how the government should be involved and how to limit negative outcomes from a positive intended action.

\section{Business Impact}

The government also has a tremendous ability to influence how companies operate; this is not as straightforward or obvious as the effect legislation and regulations that define the boundaries within which companies can act are, but rather through indirect methods that encourage companies to do certain things and discourage them from taking on other activities. This influence can actually be even stronger than through laws and regulations.

\section{FASB Rules}

Changes to the tax code are another, less obvious, avenue that the government has to influence the actions of corporations. By taxing different income and expense items differently, the government can motivate corporations to take different actions and also discourage some actions. The Federal Accounting Standards Board (FASB) decisions which outline how different accounting activities can be executed, and state what is legal and illegal in the process of preparing income statements and profit \& loss reports can also drive companies to take or not take different actions. These two together can encourage or discourage corporations to move in specific directions, especially as it relates to the types of technology or operations that companies should invest in, or avoid.

\section{Capitalize Intangibles}

Until 2002, US GAAP (Generally Accepted Accounting Practices) didn't allow Intangibles to be capitalized; they were required to be expensed as the expenditure occurred.(Callimaci \& Landry, 2002) Given that the US Government (e.g. the IRS, SEC, etc.) relies on GAAP rules to dictate how companies can calculate corporate profits, income statements and other financial details of corporate performance, any changes to these rules can present a strong motivation or obstacle for companies. Expensing a cost to a company directly reduces the revenue amount available to a corporation and, therefore, reduces profits on a one-to-one ratio. Capitalization allows the company to set aside the cost and only show small portions of that expense over the years that the capitalized item is in use by the firm, thereby boosting profits. Companies are motivated to invest in items they can capitalize and tend to reduce expenditures on items that they can't.

The original US GAAP rule, SFAS (Statement from the Financial Accounting Standards Board) 2 required all R\&D spending to be expensed.(Callimaci et al., 2002) In 1985, the same body started to make amendments to this with SFAS 86, which targeted software developed by technology companies for sales to other firms. That new rule allowed the capitalization to be applied to any software development.(Aboody \& Lev, 1999) This allowed capitalization of the R\&D spending on software technology innovations, but only after the product could pass a feasibility test.(Callimaci et al., 2002) Although SFAS 86 made room for capitalization, it didn't require it. Only a few firms utilized this advantage, to mixed results.(Aboody et al., 1999)

A bigger change came in 2002, with SFAS 141 and 142. SFAS 141 specifically covers accounting for business combinations (mergers and acquisitions); SFAS 142 covers the accounting for goodwill and other intangibles.(Donohue \& Vallario, 2002; Pretash, 2002; Quick \& Goldschmid, 2002) These two standards, in unisons, were specifically related to some of the historical research, since much of the research was based on how acquiring firms realized goodwill for the R\&D and other intangibles of purchased firms. Also, goodwill was historically the only accounting category that could account for the value added to a company from its R\&D investments its investments in other intangibles like innovation, process and a firm's human resources.(Donohue et al., 2002)

With SFAS 141 and 142, companies will not be able to lump their intangibles with goodwill, they will have to be accounted for, capitalized and amortized over the useful life of the item or process.(Quick et al., 2002) There are 
a good many "holes" that have been left for accounting professionals to define, but the impact on technology innovation should be positive and result in increased motivation for companies to invest in R\&D and ultimately new technology innovation opportunities.

\section{Monopoly Indictments}

The government also has a macro effect on corporate competition through the US Attorney General and the Federal Trade Commission. Every economy based on capitalism has to create a mechanism to deal with monopoly, as it is a natural occurrence within that economic solution. The US government has decided to "break-up" companies that have gotten too much control of their industry and/or begun to seriously limit competition. This action is normally in response to the company's competitors. Evaluating the damage to consumers is left up to other outside groups and special interests and usually is an outcome when there is no competition and no controls on pricing. There is another disadvantage to monopoly, and that is the limits a monopoly places on innovation: with no competition, there is little motivation to innovate to compete. This is detrimental to society in the longer term, as it causes stagnation in the economy. If the government does not foster a competitive market the society suffers.

\section{$I B M$}

In the 1970's, in response to complaints from Telex, the government took on IBM in an effort to stop its monopoly practices which were hindering competition.(Huth \& MacDonald, 1989) Although it took nearly a decade working through the courts, IBM changed its approach to mainframe computing and hardware manufacturing and gave way to a much more competitive environment. The end result of the government's involvement in this was more competition; it could be argued that from this increased competition the innovation pace in computing picked up as well. After all, in the 1980's and beyond the pace of computing innovation and implementation slowly started to integrate into all areas of commerce and the economy and build upon itself as more and more companies became involved and found opportunities for products, services and profits.

\section{Microsoft}

The government's monopoly case against Microsoft was very different from the one against IBM. By the 1990s, computing had already grown tremendously and resulted in many competitors, the biggest problem was too many platforms and options. Microsoft developed an operating system and then a base of white-collar productivity tools which defined the standard for all businesses, it had the Dominant Design. The monopoly was necessary to settle the issues that were hindering future innovations. The problem that the government had was the way that Microsoft was leveraging its required monopoly on the platform and trying to extend it to all other products. In truth, their monopoly on the platform was necessary, but not immediately; the innovation and Dominant Design process on those platforms (Operating System and Productivity Tools) were healthy and vigorous. Without healthy competition in the innovation phase and the opportunity for any company to develop the Dominant Design, the process is hurt and the best outcome is not settled upon. If Microsoft uses its existing platform monopoly to secure control in every future platform, it is hurting the innovation process by diminishing the opportunities for others to be involved in the process. Ultimately, this could result in slower and lesser efforts by Microsoft to innovate and utilize Creative Destruction in moving the technologies forward.

\section{MONOPOLY TECHNOLOGY}

Technology is somewhat unique in its formulation in that it is closely aligned with the network concept; the more users who are involved or use a technology the more valuable that technology is to all users, not only because of economies of scale, but also because of reduced risk of competing technologies. There has always been a high risk of lost investment for early adopters; it is the Dominant Design decision that defines the timeline from early adopters to mass acceptance. Unfortunately, this often means that technology requires a single standard in order to be most useful to users. There are risks from multiple applications and designs, as outlined earlier. There are also risks that once a technology is established, it will be difficult to replace, even with an improved technology. 


\section{Positive Impact}

When it comes to technology and technology innovation, often a monopoly or monopoly-like arrangement is best for an industry. Once the unsettling period where no dominant technology exists is over, companies can start to seriously invest in the new technology, both as users and providers. Technology providers will also only begin to make incremental innovations to a base technology, once the Dominant Design is establish. There is too much risk prior to the establishment of the Dominant Design for purchasers as well as manufacturers of goods based on the technology, as history has shown repeatedly.

\section{Railroad Tracks}

An early example of the excess costs involved with multiple implementations of a technology is the railroad. During the early years of the implementation of the railroad throughout the US, multiple standards for the gauge of the railroad track were in use. There were significant limitations to the mass use of the railroad due to the different track widths as standards in different parts of the country. Locomotive and railroad car manufacturers having to make products to multiple standards were actually minor compared to the problem of actually using the railroad. Shippers who had to have their goods cross regions with different standards were hit with increased costs, as different "trains" would have to carry in each region. It wasn't until the current track width was set as the standard that transnational railroad shipping really became a reality for the country. This new technology encouraged even greater economic advancement throughout the country.(Puffert, 2000)

\section{Personal Computers}

A more recent example, but with a similar impact on the US economy, was the standardization of the platform for PC operating systems. Prior to Microsoft Windows becoming the Dominant Design for PC operating systems, PC buyers and software developers were very cautious in their investments in PCs. Once business users were confident in the long-term viability in Windows as the operating system for PCs, manufacturers only needed to create one type of PC, rather than different PCs for different operating systems, and PC buyers felt confident that if they purchased Windows based PCs, they would be able to use them for all of their work, and share their output with other users. Software developers were able to better focus their development efforts and increase their investments in each product, since they were not required to create multiple versions of each product for multiple operating systems. The tremendous boom in productivity in the US in the late 1990's was often directly related to the productivity increases in the white-collar market,(Greenspan, 1998) and much of this was due to the application of computer-based systems to white-collar activities,(Farrell, 2003) and these systems really started to develop when software manufacturers only had to write to one standard.

\section{Roadblocks}

On the contrary, a monopoly holding a Dominant Design in technology can hurt the economy after that technology has been firmly established and entrenched. Manufacturers, and to some extent, users are either resistant to replace their current investment with a new investment based on a new technology or hesitant to invest in something that isn't yet a dominant design. This has been mentioned before, but some common examples will help to reinforce the reality of this likelihood.

\section{Blocking Innovation}

The need for a monopoly technology platform can also hinder innovation and damage the competitive process by blocking future innovations and the creative destruction that is inevitable. This isn't a new phenomenon, but rather a part of any technology innovation cycle. The company or group that controls the Dominant Design has a strong interest in maintaining that dominance, and even to stop innovation which may result in a replacement of their dominant design. This has been referenced by many innovators, where corporations with an immense investment in the current Dominant Design either buy the new innovation so that it is never used or simple hide the results of their own R\&D. This is a natural reaction from any company or group that has invested a lot of their resources and built 
their reputation on a single Dominant Design. Although it is understandable, it is still harmful to the economy and society in the long run.

Swiss Watch Digital Technology

An often quoted example of a business which experienced a missed opportunity is the Swiss handcrafted watch manufacturers and the quartz technology which ultimately replaced the handcrafted watch. It was actually the Swiss watch manufacturers who developed the quartz technology, but they were unwilling to give up their substantial investment in the handcrafted technology in order to switch to quartz. They also did not understand the value or capabilities of quartz; they allowed the Japanese manufactures to take it and use it.(Glasmeier, 1991) With quartz, the Japanese ultimately changed not only the global watch industry but the watch-wearing public. By producing cheap watches the Japanese gave the masses the opportunity to purchase a watch, rather than only those who could afford the very expensive handmade watches produced by the Swiss Consortium. This resulted in a whole new industry, with the Swiss losing control and the market for watches changing drastically.

\section{Limitations to Incremental Improvements}

If the monopoly that company has on its Dominant Design is too strongly guarded or protected, the company may not only resist the replacement of its technology with another, but also any improvement on its own design by outsiders which might limit their control of the technology. This can truly hinder the technology, as it does not allow for the full network effects of outsider innovators. The number and type of incremental innovations that can be made to the technology are thus severely limited, and the ultimate usefulness and utility to users are reduced. This could result in a quicker transition to a new technology platform or may hinder the ultimate usefulness the technology has for society, as it will definitely lower the overall investment in the technology and the exploration of its possible uses.

\section{Apple Macintosh}

The extreme control of a technology design by its inventor dealt itself the ultimate disadvantage in the case of Apple Computer and its Macintosh operating system. Apple would not allow any other software developers to add software applications for its system or any utilities developers to add functionality to it or any hardware manufacturers to also produce a Macintosh based computer. Over time, investment and research in the PC market favored the Intel/Windows-machines, not because they had the better design, but because they afforded more profitable opportunities to investors and researchers. Customers, in turn, enjoyed more options from greater competition for the technology innovations; they got more utilities from the Intel/Windows PC than the Apple Macintosh. In summary, because of the unwillingness of Apple to share in its technology and its future innovations, they ended up losing an early lead in the market.

\section{BUSINESS CYCLES}

Business Cycles have been used to explain the boom and bust nature of capitalist economies since the early part of the $20^{\text {th }}$ Century. Economist use variations on this theme to explain and predict how the economy, and much more often the labor market, will act and react to changes in the US and Global economies. Much of the early work on business cycles centered on inventory levels and how the build up and then surpluses in them would drive the economy to grow and then shrink and then grow again. Politicians have often used the 7-year Business Cycle as the cause of increases in unemployment and reductions in GDP. The Business Cycle is commonly thought of as an inevitable part of a capitalistic economy with a manufacturing base, which uses inventory as a buffer for changes in sales trends. As the importance of technology and the magnitude of its impact on the economy and the market have increased, some economists have started to take the effects of technology, and to some extent, technology innovation into account within the newer theories on business cycles. 


\section{Technology and Labor's Negative Relationship}

To better understand the theory of business cycles, one must review the basic principle of production. A simplified version of the input/output model is:

Labor + Materials + Process $=$ Output

Technology affects this model mainly at the process input, although there are some instances where the technology could be a new material. How technology affects process is most important in this analysis. One theory is the addition of technology is negatively related to labor, in other words, technology reduces the amount of labor necessary. (Basu, 1998) This theory proposes that because of "sticky prices" and the relationship of price and demand, as more technology is added to the production process, the amount of labor in use is diminished. This leads to two alternative possibilities, beyond just the shrinking of the demand for labor.

1. If price is sticky, but only in the short run, firms could actually drop price and stimulate demand, and thus produce and sell more products given a flat labor pool. This should result in greater profits for firms, thus greater benefit to society from greater output, lower prices, and maintaining the same labor pool.

2. If price remains sticky in the long run, then there is excess labor that can be used to produce other goods and services, such that the application of technology again increases output, without necessarily increasing unemployment.

These models show how technology and technology innovations have a positive effect on the economy and society. The experience of the 1990's leads one to suspect that the first possibility did materialize, as unemployment didn't fall during the late 1990's although prices fell and output rose along with productivity.

\section{Research \& Development}

There have been other responses to the need to include technology in the economic theories. One most interesting one is by Renaud Bellias, which focuses on the importance of Research and Development for the growth of an economy.(Bellias, 2004) This theory points out that there is pressure on corporations to reduce spending on R\&D to save money. The theory also relies on the premise that overall spending on $R \& D$ is good for an economy and grows output, presumably for many of the same underlying reasons as those stated by Basu. Bellias argues that in order to maintain economic growth, public funding should be used to supplement the reduction in R\&D spending by firms.

This points out that although spending on $R \& D$ is expected to increase technology innovation, which will ultimately lead to economic growth via greater output, firms are also hesitant to invest in R\&D because of the risk associated with R\&D and the likelihood that they will get no real return on their investment. Thus there is a social benefit to finding a way to reduce the risk of firm's investment in R\&D, and in ensuring that investment in technology innovation continues.

\section{REGULATORY INNOVATION MODEL}

The government can and does affect the direction that commerce heads. The government also has a vested interest in growing the economy and keeping unemployment levels low. National economic growth is assisted by R\&D investment and technology innovation. This leads to the need for a model to find a way for firms to be able to continue to invest in technology $R \& D$ and reduce the risks of investment waste. One of the most critical portions of the technology innovation process, as outlined by Tushman and Anderson, is the Design Competition Era due to high investment risk. During this era firms are competing to find a Dominant Design, which has been shown to not necessarily be the best technical solution, but rather the solution that lasts the longest and/or works best for the most entities involved. Therefore, there needs to be a process through which the design phase can be shortened, so that the Era of Incremental Change and Development of complimentary products or services can commence as early as possible. 


\section{Legal and Regulatory Struggles}

Using the Tushman and Anderson Eras Model as a basis for a Model of Regulatory Involvement in the Innovation Process; there are 3 phases that occur in this new model that relate to the 3 main Eras in their model, but with slightly different timing. The first phase, which starts after the Era of Substitution, is characterized by legal and regulatory struggles between the old technology platform and the new technology and, at later dates between, different implementations for the technology innovation. This is where the friction between the companies that are tied to the old technology start to occur with the companies that are investing in the new technology and where the competing implementation designs are vying for dominance. The transition from the first set of frictions to the second is when the innovation cycle moves from the Era of Substitution to the Era of Design Competition. If there is a regulatory environment in which the technologies operate, then the regulators will get drawn in to the competition, with each side arguing very strongly to get the regulators to agree with their position.

If the government is focused on ensuring that the Design Competition produces the best result, then the regulators involved will allow some of the new technology designs to continue, but will not support the existing technology, unless it is found that the new technology does not improve on the old technology and merely an incremental improvement. The government should be concerned with maintaining the healthy competition between the design options, without having the competition continue for too long. The optimal time length for the competition is when all of the reasonable innovators have had an opportunity to showcase their designs and have the parties interested in the technology; those firms that will be involved in creating new uses for the technology and that will create incremental improves on the design, review and evaluate their designs.

\section{Regulatory Review and Rewrite}

With the government taking an interest in optimizing the innovation process, regulators will be responsible to control the technology's design and availability for competitor improvements. Therefore, as the Design Competition reaches the final stages, near the point where a Dominant Design is being settled on, the regulators need to ensure that the monopoly holder of the old design do not stand in the way of the new technology designs being reviewed and accepted. The regulators need to start changing their rules and guidelines to remove the protections for the old Dominant Design and prepare for an environment where a new Dominant Design is selected and improved upon. This is a very difficult phase where much is in flux; the holder of the old monopoly is seeing its cash cow near its end of the cycle, the innovators in the Design Competition are pushing their designs to be the Dominant Design, and the companies that are planning to be involved with products, services and process that will utilize the new Dominant Design are starting to push to create new opportunities for revenues and profits. This phase is where the regulators are pushing quickly to select the Dominant Design, but not too quickly such that all true competitors have an opportunity to participate. With more experience with this process, all parties will mature and improve their involvement, but one of the unique aspects of innovation and technology innovation is that the new technology and new Dominant Design could very easily be developed by an organization with no previous experience with this process.

\section{Dominant Design Monopoly}

The final phase in the model for regulatory involvement begins when the new Dominant Design is selected. At this point the regulators need to ensure that the holder of the new Dominant Design does not limit the incremental improvements or possible uses of the new technology, and that society is able to extract the maximum benefit from its' opportunities. The regulators need to ensure that the information necessary for competitors to create incremental improvements and for partners to create complimentary uses have the information necessary to do so. The regulators also need to protect the Dominant Design from being stolen by competitors, as more information about the technology will be made available to allow competitors to improve and partners to innovate. This is a very delicate balance in allow a Dominant Design (monopoly) to exist without getting to the point that the monopoly reduces or destroys competition.

As the use of the Dominant Design progresses and multiple incremental improvements are made, regulators will need to monitor the environment to ensure that any budding technology isn't blocked or hindered by the 
companies dependent on the existing Dominant Design for revenue and profits from flourishing. They also need to ensure that before they abandon the existing Dominant Design, that the replacement technology really is a totally new technology along the lines of Creative Destruction, and not just an incremental improvement.

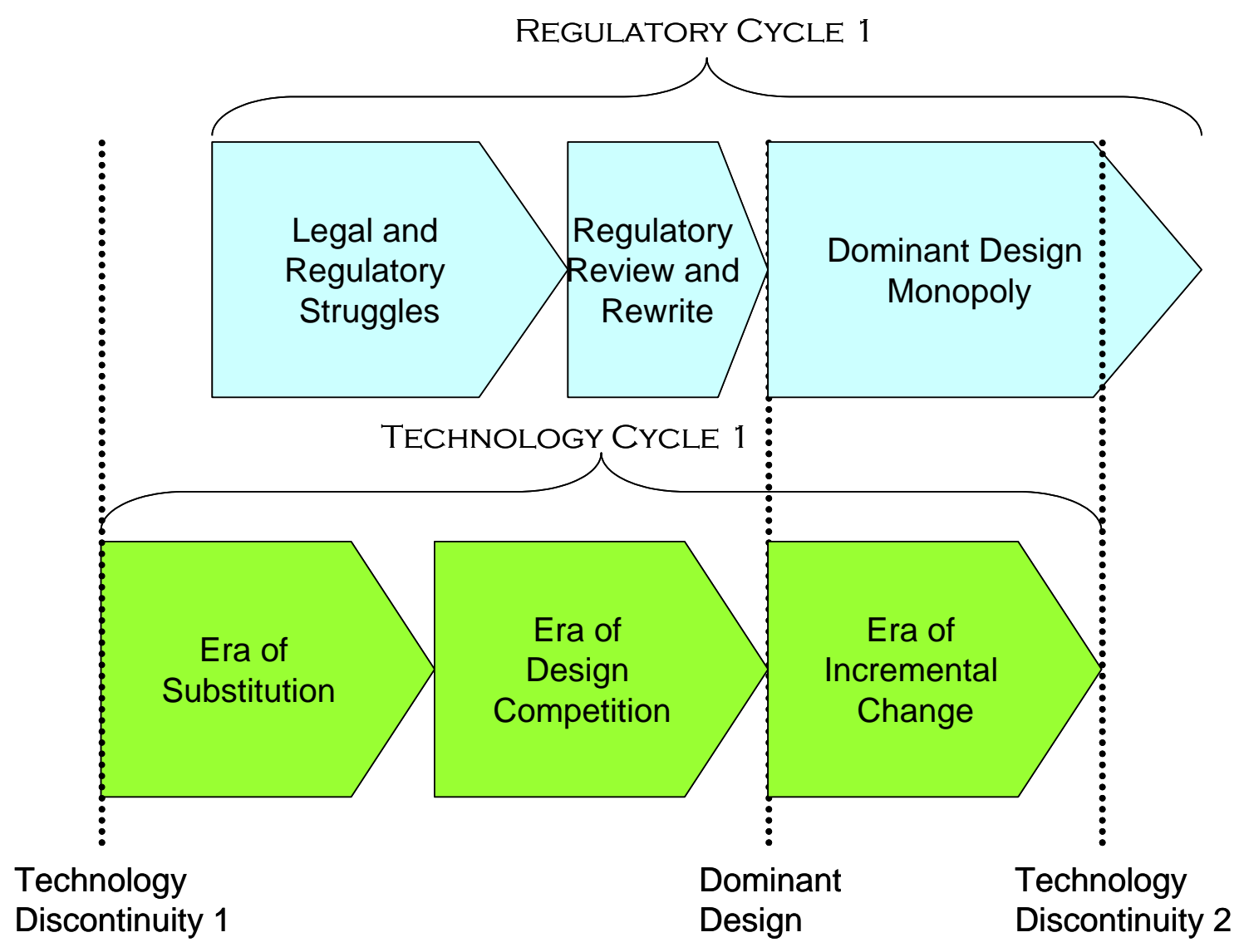

Figure 2 - updated from (Anderson et al., 1991)

\section{IMPLEMENTATION}

The model presented, if executed without prejudice against or favoritism for any company or group, should allow for an extremely productive and efficient innovation process for all technologies, even those that do not currently exist. This is not to say that it will be easy to implement, as governments are made up of people. Because people have self-interest and prejudice, they are tempted to influence the government intervention portion of the process to enrich themselves. Further, the current Regulatory Process, which is the closest government model relating to this sort of process, is far from flawed, and will not work with a direct translation. The most important aspects of government involvement lead to the biggest challenges and greatest likelihood of failure.

\section{Government Selects a Dominant Design}

Although there are many examples of government involvement that results in failures or harm to the economy (many of them already described in this paper), that is not to say that there are no successes. There have been successes, some quite obvious and others not so obvious. There are technologies that have evolved out of a technology platform that was actually developed by the government. In the US they often emerge from the 
Department of Defense; a good example is GPS (Global Positioning Satellites), which is now very popular and become quite pervasive in a number of new products. There are other examples where a government has gotten involved with the innovation cycle and stopped the Dominant Design Competition with the selection of a Dominant Design.

\section{European Union - GSM}

A contemporary example in which a governmental body got involved with the innovation process and ended the Dominant Design competition is GSM: the European Union decided to license only GSM (Global Standard for Mobile communications) for cellular telephony throughout Europe. By settling on a single platform, the European Union opened up the door for all service providers and manufacturers to innovate on the cellular telephone that was the Dominant Design and to build their markets from that platform. This not only allowed European companies to focus their investment on the GSM Dominant Design, but also reduced the fears of consumers in purchasing a cellular telephone. The end result was an early dominance of the global cellular telephone market by the Europeans as well as the dominance in consumer adoption of the technology. The US, by not selecting one single technology platform, was left with a patchwork of conflicting technologies that limited service provider competition for consumers and required manufacturers to build to multiple platforms. In the end, the US received less investment in new hardware and other innovations, and had a slower adoption rate for cellular telephony that in Europe and Asia.

\section{CONCLUSION}

Although the adoption of the Model for Regulation of Technology Innovation is fraught with challenges and possibilities for corruption, the level of impact that technology has on the economy is so great that any economic model that ignores the impact of technology and influence of technology innovation will be prone to errors in predicting economy activities. The economy has been fundamentally changed by the pervasiveness of technology and therefore the innovation cycles of technology must be incorporated into our economic models. Since the government has historically based most of its decisions regarding market intervention on an economic or business model, it is imperative that a new model be accepted which outlines more effective path of action for the government, given this technology impact. In encouraging the most productive process for technology innovation the government can stimulate more efficient economic advancements and reduce the length of stagnation in the business cycles as they are now more influenced by the cycles of technology innovation and the evolution of Dominant Designs that affect each industry. Just as the government has reacted to the economy based on previous economic models, it needs to take this new model into consideration in order to provide a more potent impact on the economy and to reduce the down cycles while encouraging more positive economic activities.

\section{BIBLIOGRAPHY}

1. $\quad$ 1998. "Senate Passes Digital Millennium Copyright Act of 1998". The Computer Lawyer, 15(7): 30.

2. $\quad$ 2003. "Retail Tech Trends", Retail Merchandiser, Vol. 43.

3. Aboody, D., \& Lev, B. 1999. "The Value Relevance of Intangibles: The Case of Software Capitalization". Journal of Accounting Research, 36: 161 - 191.

4. $\quad$ Agresti, W. 2000. "Knowledge Management". Advances in Computers, 53: 171.

5. $\quad$ Anderson, P., \& Tushman, M. L. 1991. "Managing Through Cycles of Technology Change". Research/Technology Management: 26.

6. Aufderheide, P. 1999. Communications Policy and the Public Interest. New York: The Guilford Press.

7. $\quad$ Baker, S., Green, H., \& Hof, R. D. 2004. "Click the Vote", BusinessWeek: 102.

8. Basu, S. 1998. "Technology and Business Cycles: How well do Standard Models explain the facts?" Paper presented at the Beyond Shocks: What causes Business Cycles, Boston, MA.

9. Bellias, R. 2004. "Post Keynesian theory, technology policy and long-term growth". Journal of Post Keynesian Economics, 26(3): 419 - 440.

10. Callimaci, A., \& Landry, S. 2002. Capitalization of Development Costs: A Canadian Perspective. Montreal, Quebec: Universite du Quebec a Mantreal.

11. Conhaim, W. W. 2004. "Campaigning on the Web", Information Today, Vol. 21: 25. 
12. Donohue, J., \& Vallario, C. W. 2002. "A New Scorecard for Intellectual Property". Journal of Accountancy, 193(4): 75-79.

13. Dreazen, Y. J. 2000. "Greenspan is Cautious about Rising Energy Costs", Wall Street Journal, Eastern ed.: A.2. New York, NY.

14. Elkin-Koren, N. 2000. "The Privatization of Information Policy". Ethics and Information Technology, 2: 201 - 209.

15. Farrell, D. 2003. "The real new economy". Harvard Business Review, 81(10): 104.

16. Glasmeier, A. (Ed.). 1991. Technological Discontinuities and Flexible Production Networks. New York: Oxford University Press.

17. Greenspan, A. 1998. "Statement to Congress. In U. S. C. Joint Economic Committee" (Ed.). Washington D.C.: Federal Reserve Bulletin.

18. Hart, S. L., \& Milstein, M. B. 1999. "Global Sustainability and the Creative Destruction of Industries". Sloan Management Review (Fall 1999): 23 - 33.

19. Huth, W. L., \& MacDonald, D. N. 1989. "The Impact of Shareholder Litigation on Shareholder Return". The Journal of Industrial Economics, 37(4): 411 - 426.

20. Kassicieh, S. K., \& Walsh, S. T. 2004. "Models for the commercialisation of disruptive technologies". International Journal of Technology Transfer \& Commercialisation, 3(2): 187.

21. Noe, R. A. 2005. Employee Training and Development (3rd ed.). New York, NY: McGraw-Hill Irwin.

22. Pretash, G. 2002. "New Pressures on Valuing Acquired Tangibles". Mergers and Acquisitions, 37(5): 42-45.

23. Puffert, D. J. 2000. "The Standardization of Track Gauge on North American Railways, 1830-1890". Journal of Economic History, 60(4): 933-960.

24. Quinton, A. 2004. "Adam Quinton's Testimony to Congressional Subcommittee on the State of Competition in the Telecom Industry", The Telecommunicator. New York, NY: Merrill Lynch \& Co.

25. Russell, C. 2003. "A Tough Act to Follow". School Library Journal: 52.

26. Saccomano, A. 2003. "Bar Code Technology". The Journal of Commerce: 16.

27. Schumpeter, J. 1942. Capitalism, Socialism and Democracy. New York: Harper \& Brothers.

28. Sengupta, J. K. 2001. "A model of Schumpeterian dynamics". Applied Economics Letters, 8: 81 - 84.

29. Spar, D. 2001. Ruling The Waves. New York: Harcourt Inc.

30. $\quad$ Wailgum, T. 2004. "Tag, Your Late", CIO, Vol. 18: 50. 


\section{NOTES}

